\title{
ERRATUM
}

Baus Mirela $\cdot$ Medjugorac-Popovski Mila

Dennis Brown · Sabolic Ivan

\section{In colchicine-treated rats, cellular distribution of AQP-1 in convoluted and straight proximal tubule segments is differently affected}

Published online: 14 February 2000

(C) Springer-Verlag 2000

Eur J Physiol (1999) 439:321-330

In the above article, the authors' surnames and first names were transposed. As a result the surnames were abbreviated and the first names written in full. The list of names should read as follows:

Mirela Baus, Mila Medjugorac-Popovski, Dennis Brown, Ivan Sabolic

The online version of the original article can be found at http://dx.doi.org/10.1007/s004249900187

B. Mirela $\cdot$ M.-P. Mila $\cdot$ S. Ivan (

The Unit of Molecular Toxicology,

Institute for Medical Research and Occupational Health,

Ksaverska cesta 2, 10001 Zagreb, Croatia

e-mail: sabolic@mimi.imi.hr

Tel.: +385-1-4673188, Fax: +385-1-4673303

D. Brown

The Renal Unit and Program in Membrane Biology,

Massachusetts General Hospital, 149 13th Street, Charlestown,

MA 02119, USA 